risk in many different contexts (including cultural, geographical and political), where flexibility through use of cost-benefit analyses is a standard practice. This process would benefit the IPCC WGII by widening the pool of research and practical solutions covered, making the reviews more relevant to decision-makers and by incorporation of more transparent language and terminology (such as climate change resilience) in future assessments.

The IPCC process provides the most compelling account of evidence about climate science through the working group reports and yet, the forthcoming Synthesis Report would benefit significantly from incorporation of practitioner experience of climate solutions implementation. Co-production of knowledge, across academic, political and practitioner communities, would frame, structure and deliver climate action. Such a process will ensure that future IPCC reports are more up-to-date, robust and complete in their analysis and that the climate change resilience solutions proposed incorporate the most practically viable research.
David Viner ${ }^{*}$ is at Mott MacDonald,

Demeter House, Station Road, Cambridge

CB1 2RS, UK. Candice Howarth is at the Global Sustainability Institute, Anglia Ruskin University, Cambridge CB1 1PT, UK.

*e-mail:david.viner@mottmac.com

References

1. http://go.nature.com/H9a8 $\mathrm{Nq}$

2. Coumou, D. \& Rahmstorf, S. Nature Clim. Change 2, 491-496 (2012)

3. http://go.nature.com/DRhXIx

4. Conway, D. \& Mustelin, J. Nature Clim. Change 4, 339-342 (2014)

. Pidgeon, N. \& Fischhoff, B. Nature Clim. Change 1, 35-41 (2011)

\title{
Betting on negative emissions
}

\author{
Sabine Fuss, Josep G. Canadell, Glen P. Peters, Massimo Tavoni, Robbie M. Andrew, Philippe Ciais, \\ Robert B. Jackson, Chris D. Jones, Florian Kraxner, Nebosja Nakicenovic, Corinne Le Quéré, \\ Michael R. Raupach, Ayyoob Sharifi, Pete Smith and Yoshiki Yamagata
}

\section{Bioenergy with carbon capture and storage could be used to remove carbon dioxide from the atmosphere. However, its credibility as a climate change mitigation option is unproven and its widespread deployment in climate stabilization scenarios might become a dangerous distraction.}

r uture warming will depend strongly on the cumulative $\mathrm{CO}_{2}$ emissions released through to the end of this century ${ }^{1,2}$. A finite quota of cumulative $\mathrm{CO}_{2}$ emissions, no more than $1,200 \mathrm{Gt} \mathrm{CO}_{2}$, is needed from 2015 onwards to stabilize climate below a global average of $2{ }^{\circ} \mathrm{C}$ above pre-industrial conditions by 2100 with a likelihood of $66 \%$. This corresponds to about 30 years at current emissions levels ${ }^{3}$. However, during the past decade, emissions from fossil fuel combustion and cement production have increased substantially to $36.1 \pm 1.8 \mathrm{Gt} \mathrm{CO}_{2} \mathrm{yr}^{-1}$ in 2013 (refs 4,5), projected to reach $37.0 \pm 1.8 \mathrm{Gt} \mathrm{CO}_{2} \mathrm{yr}^{-1}$ in 2014 (ref. 3), 65\% above their 1990 level. Staying within the $2{ }^{\circ} \mathrm{C}$ limit in a costeffective way will require strong mitigation action across all sectors, with greater effort needed the longer mitigation is delayed.

Actions that could stabilize climate as desired include the deliberate removal of $\mathrm{CO}_{2}$ from the atmosphere by human intervention - called here 'negative emissions'. Along with afforestation, the production of sustainable bioenergy with carbon capture and storage (BECCS) is explicitly being put forth as an important mitigation option by the majority of integrated assessment model (IAM) scenarios aimed at keeping warming below $2{ }^{\circ} \mathrm{C}$ in the IPCC's fifth assessment report (AR5) 6 . Indeed, in these scenarios, IAMs often foresee absorption of $\mathrm{CO}_{2}$ via BECCS up to (and in some cases exceeding) $1,000 \mathrm{Gt} \mathrm{CO}_{2}$ over the course of the century $^{7}$, effectively doubling the available carbon quota.

BECCS is the negative emissions technology most widely selected by IAMs to meet the requirements of temperature limits of $2{ }^{\circ} \mathrm{C}$ and below. It is based on assumed carbon-neutral bioenergy (that is, the same amount of $\mathrm{CO}_{2}$ is sequestered at steady state by biomass feedstock growth as is released during energy generation), combined with capture of $\mathrm{CO}_{2}$ produced by combustion and its subsequent storage in geological or ocean repositories. In other words, BECCS is a net transfer of $\mathrm{CO}_{2}$ from the atmosphere, through the biosphere, into geological layers, providing in addition a non-fossil fuel source of energy. Other options include afforestation, direct air capture and increases in soil carbon storage. Afforestation and increased soil carbon storage differ from BECCS in that these land-use and management changes are associated with a saturation of $\mathrm{CO}_{2}$ removal over time, and in that the sequestration is reversible with terrestrial carbon stocks inherently vulnerable to disturbance ${ }^{8}$.

\section{The need for negative emissions}

The IPCC's Working Group 3 (WG3) considered in AR5 over 1,000 emission pathways to 2100 (Fig. 1a). Most scenarios (101 of 116) leading to concentration levels of 430-480 ppm $\mathrm{CO}_{2}$ equivalent $\left(\mathrm{CO}_{2} \mathrm{eq}\right)$, consistent with limiting warming below $2{ }^{\circ} \mathrm{C}$, require global net negative emissions in the second half of this century, as do many scenarios (235 of 653) that reach between 480 and 720 ppm $\mathrm{CO}_{2}$ eq in 2100 (Fig. 1b, scenarios below zero). About half of the scenarios feature BECCS exceeding $5 \%$ of primary energy supply. Many of those (252 of 581) have net positive emissions in 2100 (Fig. 1b). Thus, BECCS does not ensure net negative emissions (that is, its use need not completely offset all positive emissions). BECCS is an important mitigation technology, especially as the stabilization level is lowered, and if nearterm mitigation is delayed. By eventually requiring deeper emissions reductions, BECCS can help reconcile higher interim $\mathrm{CO}_{2}$ eq concentrations with low long-term stabilization targets, particularly if overshooting of concentrations is allowed. 


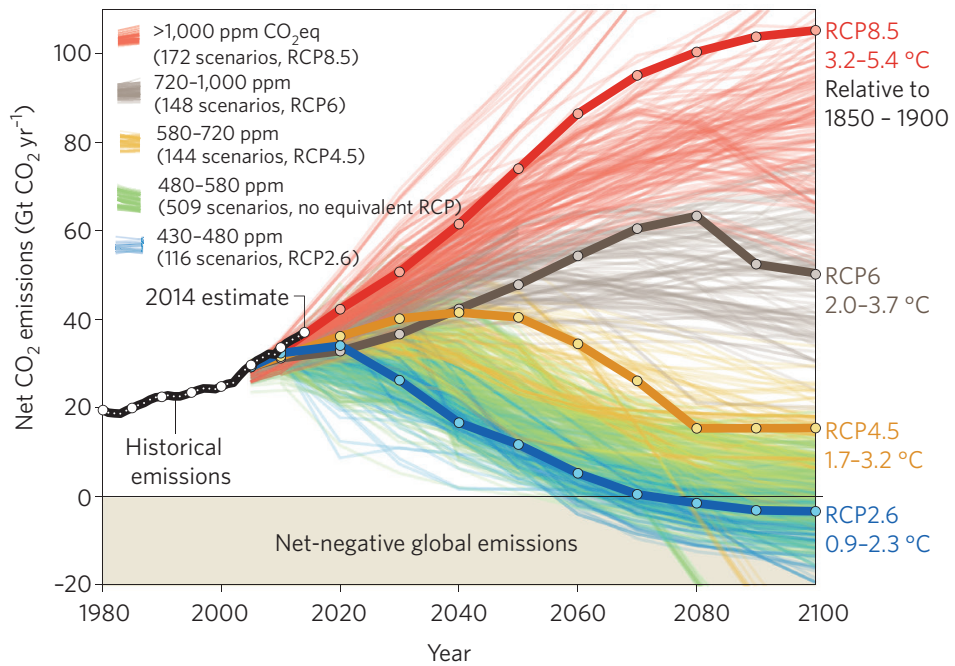

b

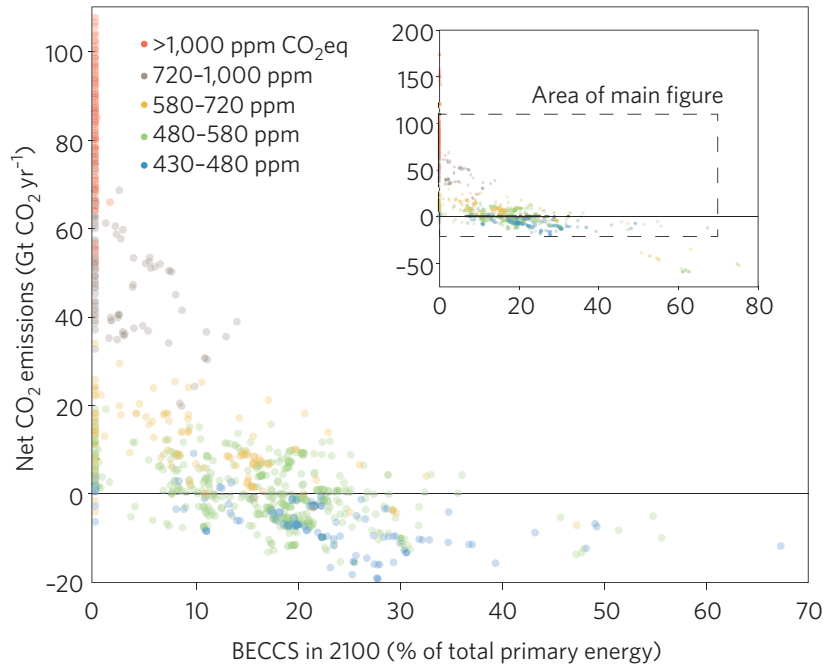

Figure 1 | Carbon dioxide emission pathways until 2100 and the extent of net negative emissions and bioenergy with carbon capture and storage (BECCS) in 2100. a, Historical emissions from fossil fuel combustion and industry (black) are primarily from the Carbon Dioxide Information Analysis Center ${ }^{4,6}$. They are compared with the IPCC fifth assessment report (AR5) Working Group 3 emissions scenarios (pale colours) and to the four representative concentration pathways (RCPs) used to project climate change in the IPCC Working Group 1 contribution to AR5 (dark colours). $\mathbf{b}$, The emission scenarios have been grouped into five climate categories ${ }^{5}$ measured in ppm $\mathrm{CO}_{2}$ equivalent $\left(\mathrm{CO}_{2}\right.$ eq $)$ in 2100 from all components and linked to the most relevant RCP. The temperature increase (right of panel a) refers to the warming in the late twenty-first century (2081-2100 average) relative to the 1850-1900 average ${ }^{24}$. Only scenarios assigned to climate categories are shown $\left(1,089\right.$ of 1,184). Most scenarios that keep climate warming below $2{ }^{\circ} \mathrm{C}$ above pre-industrial levels use BECCS and many require net negative emissions (that is, BECCS exceeding fossil fuel emissions) in 2100. Data sources: IPCC AR5 database, Global Carbon Project and Carbon Dioxide Information Analysis Center.

Taking into account the full scenario range, global net negative emissions would need to set in around 2070 for the most challenging scenarios and progressively later for highertemperature stabilization levels.

IAMs $^{6}$ and Earth system models (ESMs ${ }^{2}$ ) provide different but complementary approaches for quantifying negative emissions requirements. ESMs simulate the compatible net $\mathrm{CO}_{2}$ emissions based on mass balance between atmospheric changes in $\mathrm{CO}_{2}$ and land and ocean carbon sinks. A model intercomparison of ten ESMs found that two-thirds of the models required net negative emissions in the second half of the century ${ }^{9}$, but the ESMs make no assumption on how this is technically achieved. For IAMs, negative emissions are an outcome of an economic optimization driven by a choice between reducing emissions and BECCS (gross negative emissions). Both approaches model the link between $\mathrm{CO}_{2}$ emissions, atmospheric concentrations and subsequent climate change. Importantly, some of the non- $\mathrm{CO}_{2}$ emissions (for example, $\mathrm{CH}_{4}$ and $\mathrm{N}_{2} \mathrm{O}$ from agriculture) will be very difficult to mitigate completely, as will some $\mathrm{CO}_{2}$ emissions from industry and transportation below which mitigation will be economically and technically very difficult ${ }^{10}$. Therefore, to reach long-term climate stabilization under the $2{ }^{\circ} \mathrm{C}$ limit, there is likely to be a requirement for gross negative $\mathrm{CO}_{2}$ emissions (that is, at the project level) and likely also for net negative emissions (that is, the global net balance).

\section{The challenges ahead}

The deployment of large-scale bioenergy faces biophysical, technical and social challenges ${ }^{11}$, and CCS is yet to be implemented widely. Four major uncertainties need to be resolved: (1) the physical constraints on BECCS, including sustainability of large-scale deployment relative to other land and biomass needs, such as food security and biodiversity conservation, and the presence of safe, longterm storage capacity for carbon; (2) the response of natural land and ocean carbon sinks to negative emissions; (3) the costs and financing of an untested technology; and (4) socio-institutional barriers, such as public acceptance of new technologies and the related deployment policies. In the IAM scenarios in $\mathrm{AR} 5^{6}$ that are consistent with warming of less than $2^{\circ} \mathrm{C}$, the requirement for BECCS ranges between 2 and $10 \mathrm{Gt} \mathrm{CO}_{2}$ annually in 2050, corresponding to $5-25 \%$ of $2010 \mathrm{CO}_{2}$ emissions and $4-22 \%$ of baseline $2050 \mathrm{CO}_{2}$ emissions. Huge upscaling efforts will be needed to reach this level. In comparison, the current global mean removal of $\mathrm{CO}_{2}$ by the ocean and terrestrial carbon sinks is $9.2 \pm 1.8 \mathrm{Gt} \mathrm{CO}_{2}$ and $10.3 \pm 2.9 \mathrm{Gt} \mathrm{CO}_{2}$, respectively ${ }^{5,12}$.
Concerning the capture and storage portion of the BECCS chain, the International Energy Agency's CCS roadmap clearly illustrates that huge efforts would be needed to achieve the scale of CCS (both fossil fuel emissions CCS and BECCS) foreseen in current stabilization scenarios, as publicly supported demonstration programs are still struggling to deliver actual large-scale projects ${ }^{13}$.

It is difficult to estimate the actual costs of BECCS, as it is partially in competition for resources (land, biomass and storage capacity, and cost of CCS) used in other mitigation options and for objectives beyond climate stabilization. However, while negative emissions might seem more expensive than established mitigation options, including fossil fuel emissions CCS, the mitigation pathways to 2100 excluding negative emissions technologies are all substantially more expensive than the pathways including those technologies ${ }^{6,14,15}$.

Policymakers will need a much more complete picture of negative emissions than what is currently at hand. Issues of governance and behavioural transformations need to be better understood. The reliance of current scenarios on negative emissions, despite very limited knowledge, calls for a major new transdisciplinary research agenda to (1) examine consistent narratives for the potential of implementing and managing negative emissions, (2) estimate 


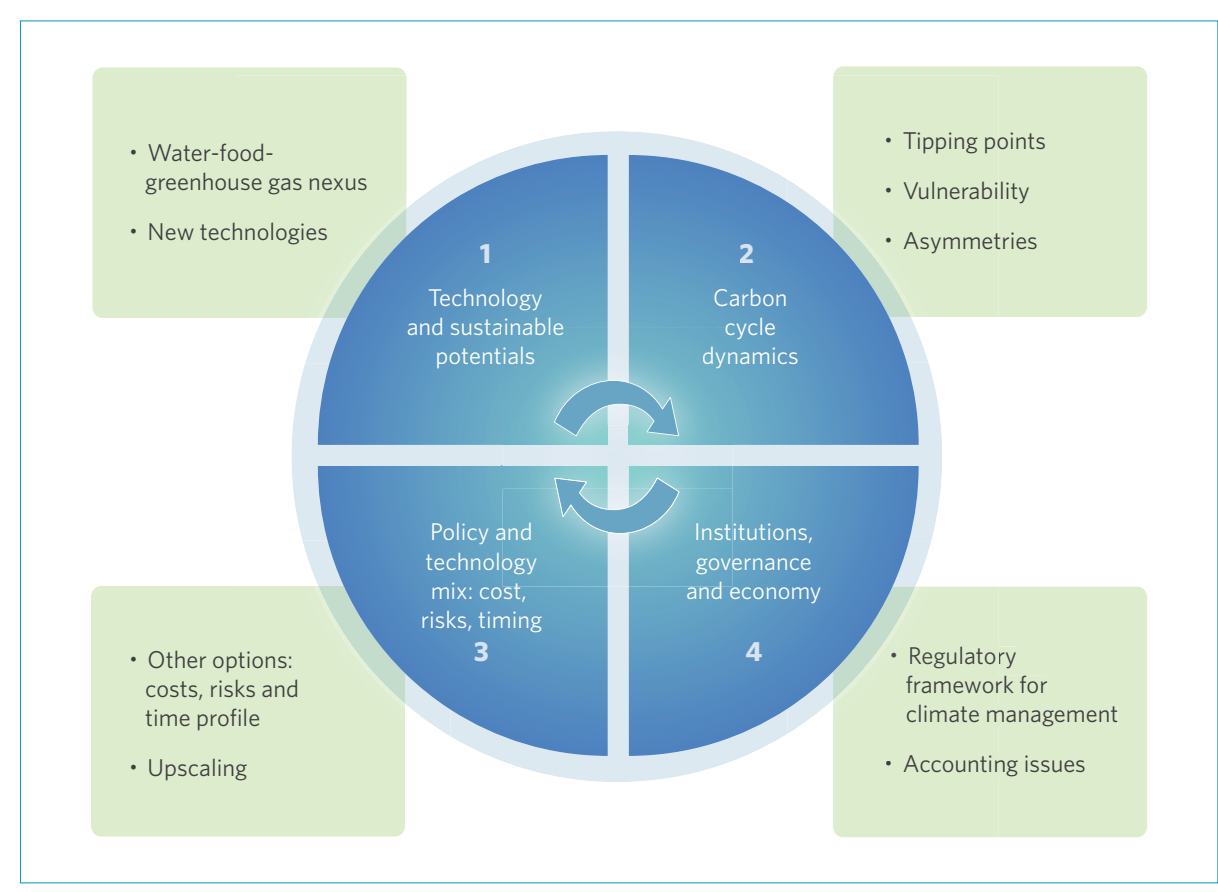

Figure 2 | The four components of consistent negative emissions narratives.

uncertainties and feedbacks within the socio-institutional, techno-economic and Earth system dimensions, and (3) offer guidance on how to act under the remaining uncertainties. Similarly, technological and institutional roadmaps, and rapid implementation of pilot projects are needed to test feasibility and understand the barriers to technological development.

In addition to characterizing the potential for negative emissions more reliably and geographically explicitly ${ }^{16,17}$, the tradeoffs related with the use of negative emissions need to be further assessed. Some recent collaborative modelling efforts have provided important insights into such potential tradeoffs (for example, ref. 18). In the case of BECCS, tradeoffs are associated with (1) competition for land and possible conflicts with the objectives for food security, biodiversity conservation and the demand for water resources in different sectors (for example, ref. 19), and (2) the existence of sufficient potential for secure and accessible storage of captured $\mathrm{CO}_{2}$ in competition with fossil fuel CCS, uncertainties about the possibility to upscale negative emissions technologies quickly and public acceptance.

A consistent narrative of negative emissions management therefore has four components (Fig. 2) relating to the key uncertainties. The first component refers to technological aspects: with BECCS being the negative emissions technology most widely applied by IAMs, the implied heavy demands for sustainable biomass availability are suggested to be at least $100 \mathrm{EJ} \mathrm{yr}^{-1}$ and up to more than $300 \mathrm{EJ} \mathrm{yr}^{-1}$ of equivalent primary energy by 2050 (ref. 20). Also, $\mathrm{CO}_{2}$ storage potential in geological layers (aquifers, depleted fossil carbon reservoirs) and other resources, such as water and fertilizer, in the face of increasing food demand will need to be addressed. Bioenergy and water recycling with solar-powered distillation, algae grown offshore and fertilized with previously captured $\mathrm{CO}_{2}$, and other innovations are among possible technologies enabling negative emissions to be achieved with lower pressure on land biomass production. However, such technologies require significant new research and development.

The second component in Fig. 2 describes carbon cycle uncertainties and dynamics in the Earth system. If negative emissions options such as BECCS are used only after significant climate change, then the response of the global carbon cycle can make the necessary amount of negative emissions even larger than for a scenario where the future $\mathrm{CO}_{2}$ trajectory is contained below $430-480 \mathrm{ppm}$. This could occur through decreasing terrestrial and ocean sink efficiencies due to climate change, and net releases of $\mathrm{CO}_{2}$ by the land and ocean reservoirs due to $\mathrm{CO}_{2}$ removal over several decades ${ }^{6,12,21,22}$.

The third component acknowledges that negative emissions will be part of a wider mitigation effort and their deployment will depend on the cost, risks and timing profile of other options. The spectrum ranges from more established mitigation technologies - for which it might then be too late - to solar-radiation management geoengineering options, which are quicker and cheaper to ramp up, but which embody a much larger scale of mostly unknown risks ${ }^{23}$ and are not able to deal with other consequences of increased $\mathrm{CO}_{2}$ concentrations such as ocean acidification. This emphasizes that we are not in a position to discard the negative emissions option easily, despite the above challenges. The fact that negative emissions solutions like BECCS will require time to achieve sufficient scale confirms that the future option space depends strongly on today's decisions.

The final component is concerned with institutional and policy challenges. $\mathrm{CO}_{2}$ removal will be expensive and contentious, whereas emissions will remain cheap in the absence of strong climate policies. Therefore, any $\mathrm{CO}_{2}$ removal strategy requires an extraordinary global regulatory framework taking into account national economic conditions. In the absence of a global climate agreement requiring stringent mitigation efforts and given the asymmetric distribution of mitigation potentials, negative emissions could help to offset emissions from countries that might not participate in reduction efforts or have less capacity to do so. This could open new perspectives on global climate management. Rigorous monitoring, reporting and verification will be needed to facilitate these options.

The development of consistent negative emissions narratives is not a call for largescale BECCS deployment, but a call to carefully and quickly assess all dimensions of its use for climate stabilization. Determining how safe it is to bet on negative emissions in the second half of this century to avoid dangerous climate change should be among our top priorities.

Sabine Fuss ${ }^{1,2 *}$, Josep G. Canadell ${ }^{3}$, Glen P. Peters ${ }^{4}$, Massimo Tavoni ${ }^{5}$, Robbie M. Andrew ${ }^{4}$, Philippe Ciais', Robert B. Jackson ${ }^{7}$, Chris D. Jones ${ }^{8}$, Florian Kraxner ${ }^{2}$, Nebosja Nakicenovic ${ }^{2}$, Corinne Le Quéré9, Michael R. Raupach ${ }^{10}$, Ayyoob Sharifi ${ }^{11}$, Pete Smith ${ }^{12}$ and Yoshiki Yamagata ${ }^{11}$ are at the ${ }^{1}$ Mercator Research Institute on Global Commons and Climate Change, Working Group Resources and International Trade, Torgauer Strasse 12-15, Berlin 10829, Germany, ${ }^{2}$ International Institute for Applied Systems Analysis, Schlossplatz 1, 2361 Laxenburg, Austria, ${ }^{3}$ CSIRO Oceans and Atmosphere Flagship, GPO Box 3023, Canberra, Australian Capital Territory 2601, Australia, ${ }^{4}$ Center for International Climate and Environmental Research - Oslo (CICERO), Gaustadalléen 21, 0349 Oslo, Norway, ${ }^{5}$ Fondazione Eni Enrico Mattei and CentroMediterraneo sui Cambiamenti Climatici (CMCC) and Politecnico di Milano, Corso Magenta 63, 
Milan, Italy, ${ }^{6}$ Laboratorie des Sciences du Climat et de l'Environnement, Centre d'Etudes de Orme des Merisiers - BAT 709, Gif sur Yvette 91191, France, ${ }^{7}$ Stanford University, School of Earth Sciences, Woods Institute for the Environment, and Precourt Institute for Energy, 473 Vio Ortega, Stanford, California 94305, USA, ${ }^{8}$ Met Office Hadley Centre, FitzRoy Road, Exeter EX1 3PB, UK, ${ }^{9}$ Tyndall Centre for Climate Change Research, University of East Anglia, Norwich NR4 7TJ, UK, ${ }^{10}$ Climate Change Institute, Fenner School, Australian National University, Canberra, Australian Capital Territory 0200, Australia, ${ }^{11}$ National Institute for Environmental Studies, Onogawa 16-2, Tsukuba Ibaraki 305-8506, Japan, ${ }^{12}$ Institute of Biological and Environmental Sciences, University of Aberdeen, 23 St Machar Drive, Aberdeen AB24 3UU, UK. *e-mail:fuss@mcc-berlin.net

References

1. Allen, M. R. et al. Nature 458, 1163-1166 (2009).

2. IPCC Climate Change 2013: The Physical Science Basis (eds Stocker, T. F. et al.) (Cambridge Univ. Press, 2013).

3. Friedlingstein, P. et al. Nature Geosci. http://dx.doi.org/10.1038/ngeo2248 (2014).

4. Boden, T. A. et al. Global, Regional, and National Fossil-Fuel $\mathrm{CO}_{2}$ Emissions (Oak Ridge National Laboratory, US Department of Energy, 2013).

5. Le Quéré, C. et al. Earth Syst. Sci. Data 6, 235-263 (2014).

6. Clarke, L. et al. in Climate Change 2014: Mitigation of Climate Change (eds Edenhofer, O. et al.) Ch. 6 (Cambridge Univ. Press, in the press).

7. Tavoni, M. \& Socolow, R. Climatic Change 118, 1-14 (2013)
8. Raupach M. R. \& Canadell, J. G. in The Continental-Scale Greenhouse Gas Balance of Europe (eds Dolman A. J. et al.) 5-32 (Springer, 2008).

9. Jones, C. et al. J. Clim. 26, 4398-4413 (2013).

10. Davis, S. J., Caldeira, K. \& Matthews, H. D. Science 29, 1330-1333 (2010)

11. Creutzig, F. et al. Glob. Change Biol. http://go.nature.com/F6JxKX (2014).

12. Ciais, P. et al. in Climate Change 2013: The Physical Science Basis (eds Stocker, T. F. et al.) Ch. 6 (Cambridge Univ. Press, 2013).

13. Scott, V., Gilfillan, S., Markusson, N., Chalmers, H. \& Haszeldine, R. S. Nature Clim. Change 3, 105-111 (2012).

14. Fuss, S., Reuter, W-H., Szolgayova, J. \& Obersteiner, M. Climatic Change 118, 73-87 (2013)

15. Kriegler, E., Edenhofer, O., Reuster, L., Luderer, G. \& Klein, D. Climatic Change 118, 45-57 (2013).

16. Kraxner, F. et al. Rene 61, 102-108 (2014).

17. Kato, E. \& Yamagata, Y. Earth's Future http://go.nature.com/nobafN (2014).

18. Popp, A. et al. Climatic Change 123, 495-509 (2014)

19. GEA Global Energy Assessment - Toward a Sustainable Future Ch. 20, 1459-1526 (Cambridge Univ. Press and International Institute for Applied Systems Analysis, 2012).

20. Smith, P. et al. in Climate Change 2014: Mitigation of Climate Change (eds Edenhofer, O. et al.) Ch. 11 (Cambridge Univ. Press, in the press)

21. Cao, L. \& Caldeira, K. Environ Res. Lett. 5, 024011 (2010).

22. Vichi, M., Navarra, A. \& Fogli, P. G. Climatic Change 118, 105-118 (2013).

23. Kravitz, B. et al. J. Geophys. Res. Atmos. 118, 8320-8332 (2013)

24. IPCC Summary for Policymakers in Climate Change 2013: The Physical Science Basis (eds Stocker, T. F. et al.) (Cambridge Univ. Press, 2013).

\section{Acknowledgements}

This work is a collaborative effort under the MaGNET

(Managing Global Negative Emissions Technologies)

initiative of the Global Carbon Project (www.globalcarbonproject.org), a joint project of the International Geosphere-Biosphere Programme, the International Human Dimension Programme on Global Environmental Change, the World Climate Research Programme and Diversitas. J.G.C. thanks the support of the Australian Climate Change Science Program. C.D.J. was supported by the Joint UK Department of Energy \& Climate Change and the Department for Environment, Food \& Rural Affairs Met Office Hadley Centre Climate Programme (GA01101). G.P.P. and R.M.A thank the support of the Norwegian Research Council (236296). Y.Y. and A.S. acknowledge that GCP Tsukuba office activities are supported by Center for Global Environmental Research, National Institute for Environmental Studies. F.K. acknowledges support from the International Institute for Applied Systems Analysis Tropical Flagship Initiative. M.T. acknowledges the Italian Ministry of Education, University and Research and the Italian Ministry of Environment, Land and Sea under the GEMINA project. C.L.Q. thanks the support of UK's Natural Environment Research Council (NE/103002X/1). R.B.J. acknowledges the US Department of Agriculture (AFRI \#2012-00857).

Author contributions

All authors contributed to the planning of the paper. S.F led the work together with J.G.C. and prepared Fig. 2 including description of the framework benefiting from discussions with all authors. G.P.P., R.M.A. and M.T. prepared Fig. 1 and/or provided the associated analysis. All authors contributed to writing the Commentary, providing comments to the framework and input in terms of numbers and references backing the analysis.

\title{
Copenhagen II or something new
}

\author{
David G. Victor
}

\section{For the first time since the failed 2009 Copenhagen Climate Change Conference, momentum is building towards a new climate agreement. But expectations must be kept in check, and making expert advice more useful to the process will require engaging the social sciences more fully.}

$$
\text { A }
$$
nother season of climate diplomacy is under way. In September, the United Nations Secretary General will host a summit of world leaders aimed at focusing political attention on the need for more stringent policies. A few months later, in December in Lima, diplomats will take stock of their efforts to negotiate a new global agreement that would take over before the Kyoto Protocol expires in 2020. After Lima, a spate of diplomatic events during 2015 will culminate at a December summit in Paris, when governments are expected to sign the new climate accord.

While this surge of diplomacy is promising, there are also disturbing parallels with the diplomatic run-up to the Copenhagen
Climate Change Conference in 2009 - an event that also had aspired to produce an agreement that would replace the outdated Kyoto treaty, but which ended in a fizzle of disagreement and dashed expectations. In the year or so before Copenhagen there were, like today, many bold pronouncements but few specifics. Massive disagreements over who would pay the cost of controlling emissions and adapting to climate change loomed large with no serious solutions in sight. And like today, the pre-Copenhagen process saw negotiators dither in the painstaking work of actually drafting an agreement - leaving too much to the final moments ${ }^{1}$.

Will Paris be another Copenhagen? While most answers to that question hinge on how politicians and diplomats behave, the scientific community can help raise the odds of success in Paris and beyond. Part of what science can do has been done: over the past 12 months the IPCC has released three massive new assessments of climate science ${ }^{2-4}$. While important uncertainties will always remain, the IPCC's new assessment - the first since 2007 - credibly demonstrates that the scientific case for action to cut emissions is stronger than ever.

Making the case that climate change is a serious problem is just one of many ways that science could guide how governments approach the policy challenges in crafting new agreements on climate change. But nearly all the information that governments 